\title{
Diagnostic value of blink reflex in multisystem atrophy, progressive supranuclear palsy and Parkinson disease
}

\author{
Elzbieta Szmidt-Salkowska ${ }^{a}$, Malgorzata Gawel ${ }^{a,{ }^{*}}$, Zygmunt Jamrozik $^{a}$, \\ Joanna Salkowska-Wanat ${ }^{b}$, Damian Gawel ${ }^{c}$, Anna Kaminska ${ }^{a}$ \\ ${ }^{a}$ Department of Neurology, Medical University of Warsaw, Warsaw, Poland \\ ${ }^{\mathrm{b}}$ Department of Dermatology and Venereology, Medical University of Warsaw, Warsaw, Poland \\ ${ }^{c}$ Centre of Postgraduate Medical Education, Department of Biochemistry and Molecular Biology, Warsaw, Poland
}

\section{A R T I C L E I N F O}

\section{Article history:}

Received 15 March 2016

Received in revised form

18 May 2016

Accepted 14 June 2016

Available online 27 June 2016

Keywords:

Blink reflex

Multisystem atrophy

Progressive supranuclear palsy

Parkinson disease

\begin{abstract}
A B S T R A C T
Abnormal blink reflex $(\mathrm{BR})$ is a result of reticular brainstem pathways dysfunction and seems to be one of the features of brain degenerative disorders.

The aim of the study was to estimate the diagnostic value of blink reflex in neurodegenerative diseases such as: multisystem atrophy (MSA), progressive supranuclear palsy (PSP) and Parkinson disease (PD).

Material consisted of 99 patients with clinically probable MSA (51), PSP (28) and PD (20). MSA patients were divided into two subgroups, with dominant cerebellar (MSA-C) and parkinsonian signs (MSA-P). The mean age of patients was 64.9 years (47-79 years); males $-55.3 \%$.

Blink reflex was obtained in a typical way.

Results: The significant differences in mean values of blink reflex latencies between PD and other subgroups (MSA-P, MSA-C, PSP) were found, but all of them were in normal range. In individual patients with PD and PSP (50\% and 18\%, respectively) delayed R2 latencies were recorded.

Conclusions: The most frequently abnormal blink reflexes, comparing the MSA, PSP and PD groups, were present in PD patients. We postulate that this may be explained by pathological influence of nigrostriatal pathway on the circuit linking the basal ganglia, cerebellum and brainstem.
\end{abstract}

(C) 2016 Polish Neurological Society. Published by Elsevier Sp. z o.o. All rights reserved.

\section{Introduction}

Multisystem atrophy (MSA) and Parkinson's disease (PD) belong to a group of $\alpha$-synucleinopathies with different localizations and pattern of synuclein pathology [1]. Progressive supranuclear palsy (PSP) is a rare taupathy which shares many clinical symptoms with MSA and PD. All of them are characterized by dopamine deficiency in subcortical nuclei, mainly in the substantia nigra and in the brainstem.

\footnotetext{
Tel.: +48 225992857; fax: +48 225991857.

E-mail addresses: ela.szmidt@wp.pl (E. Szmidt-Salkowska), mgawel@wum.edu.pl (M. Gawel), zygmunt.jamrozik@wum.edu.pl (Z. Jamrozik), Polandgawel@cmkp.edu.pl (D. Gawel).

http://dx.doi.org/10.1016/j.pjnns.2016.06.001

0028-3843/@ 2016 Polish Neurological Society. Published by Elsevier Sp. z o.o. All rights reserved.
}

* Corresponding author at: Department of Neurology, Medical University of Warsaw, Banacha 1A, 02-097 Warsaw, Poland. 
Multisystem atrophy is a neurodegenerative disease and is characterized by different clinical symptoms due to autonomic, parkinsonian, pyramidal and cerebellar signs. Based on predominant clinical symptoms (e.g. cerebellar or parkinsonian), MSA is subdivided into a parkinsonian (MSA-P) and a cerebellar (MSA-C) type [2-5]. Cellular pathology in MSA was revealed mainly in upper motor neurons, in basal ganglia and sporadically in lower motor neurons [6-8].

Progressive supranuclear palsy (PSP) is characterized by progressive degeneration of basal ganglia, brainstem, cortex, facial and trigeminal nuclei, which has been documented in neuropathological examinations, as well as in magnetic resonance imaging and positron emission tomography studies [9-15].

The level and intensity of cortex, cerebellar and/or brainstem dysfunctions in MSA, PSP and in PD could be estimated using neuroimaging methods and electrophysiological test as blink reflex (BR).

The main external control of blink reflex consists of a dopaminergic system and olivo-cerebellar circuit.

Unconditioned stimulus pathway of the eye-blink includes inferior olive and climbing fibers of the cerebellar nuclei and cortex, while conditioned stimulus consists of pontine sensory nuclei, cerebellar interpositius nucleus, superior cerebellar peduncle and magnocellular red nucleus [16-18].

Basal ganglia could modulate the brainstem reflex blink circuits via descending cortical projections or alternatively, with input to the superior colliculus via tecto reticular projections $[19,20]$.

The spinal trigeminal nucleus consists of three subnuclei and ascending/descending pathways probably exist between these subnuclei. Han et al. showed that excitatory and inhibitory synaptic responses are mediated by AMPA $(\alpha-$ amino-3-hydroxy-5-methyl-4-isoxazolepropionic acid), NMDA
(N-methyl-D-aspartate) and by GABA (gamma-aminobutyric acid) (receptors with a differential contribution to the synaptic responses between subnuclei) [21].

Neurotransmission disturbed in MSA, PSP and PD and neural pathways underlying brainstem and spinal reflexes may influence blink reflex in different way.

The reduced blinking in Parkinson's disease and excessive blinking after overstimulation by dopaminergic agents associated with dyskinesia suggests involvement of efferents of nigrostriatal system to superior colliculus and brainstem [22]. Other structures involved in delayed components of blink reflex may be brainstem, cerebellum and olivo-cerebellar circuit. As shown previously, the brainstem is involved in many extremely complicated (e.g. vocal control or auditory startle reaction) [2325]. In PSP the voluntary blinking is bradykinetic with an increased duration of opening phase without abnormalities reversed by correction of dopaminergic deficit [26].

The lesions of supratentorial could reveal prolonged, contralateral R2 latencies as a result of inhibitory inputs of pyramidal tracts to the contralateral reticular formation (afferent branch abnormality) [27].

Blink reflex is a polysynaptic reflex between the trigeminal and the facial system [28-31].

The afferent arc of BR consists of trigeminal nerve sensory fibers. The efferent arc of BR conveys the impulses through the motor fibers of the facial nerves. Blink reflex involves an early $\mathrm{R} 1$ response which terminates in midpoints. The two late bilateral R2 responses mediated by the spinal nucleus and trigeminal nerve tracts reflect the connection of trigeminal and facial systems in the lower medullary region by polysynaptic bilateral medullary pathways. They are terminated in the facial nuclei [32-37] (Fig. 1).

Likewise in Bentivollo's study, no differences in BR values between age and sex were observed [38].

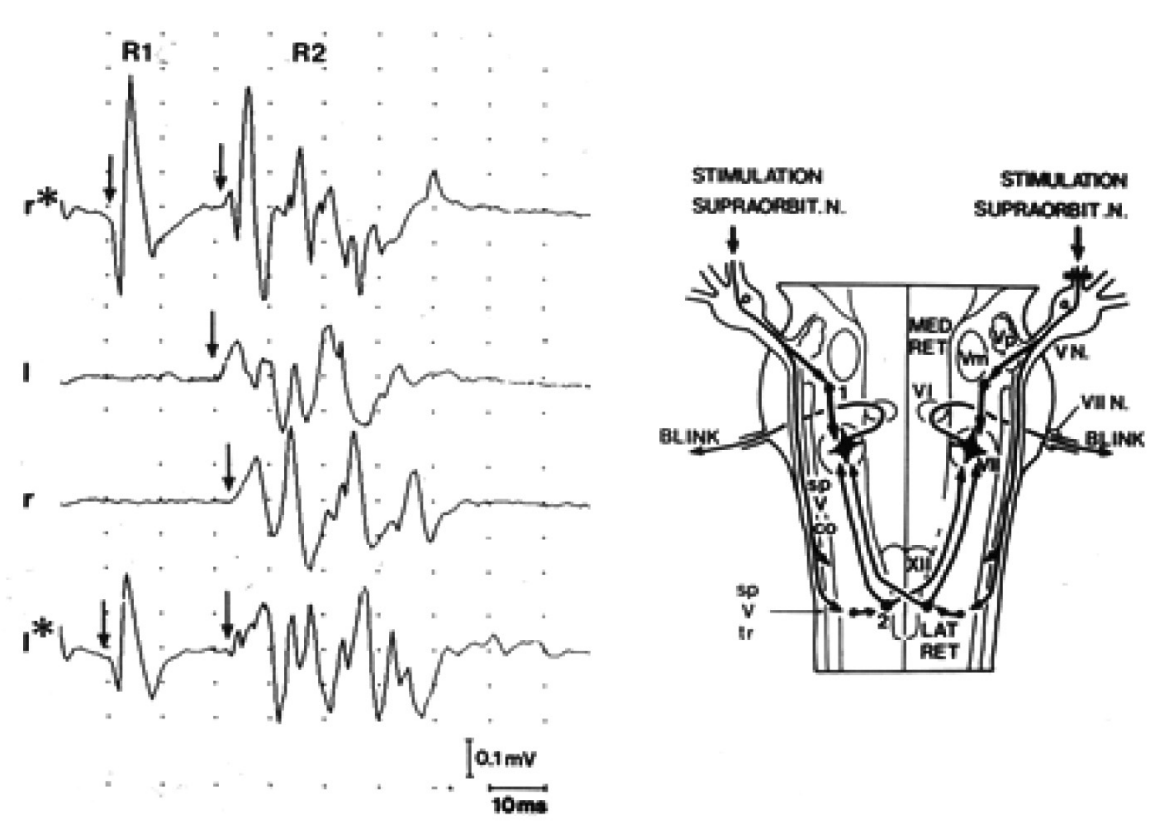

Fig. 1 - Pathways of blink reflex [39]. R1-R1 (early) response of blink reflex. R2-R2 (late) response of blink reflex. 
The aim of the study was to analyze the Blink Reflex parameters and to estimate the diagnostic value of blink reflex in MSA, PSP and PD patients.

\section{Material and methods}

A group of 99 patients with clinically probable MSA (51), PSP (28) and PD (20). The mean age was 64.9 years (males $-55.3 \%$ ).

All patients with MSA fulfilled the diagnostic EMSA-SG (European Multiple System Atrophy Study Group) criteria for probable MSA according to the second consensus statement [3]. According to their clinical prominent symptoms, patients were divided into two subgroups - with predominant cerebellar (MSA-C) and with predominant parkinsonian signs (MSA-P). MSA-C was diagnosed in 24 cases (mean age 60.5 \pm 8.5 ) and MSA-P in 27 patients (mean age $60.9 \pm 8.1$ ). The mean patients age of the disease onset for whole MSA group was 57.1 years. The mean duration of the disease was 3.5 years.

28 patients with PSP were clinically diagnosed according to National Institute for Neurological Disorders and Stroke/ Society for Progressive Supranuclear Palsy criteria and 20 cases with PD were diagnosed according to UK Parkinson's Disease Society Brain Bank Clinical Diagnostic Criteria $[9,39,40]$. The mean age of patients with PSP was $67.8 \pm 6.5$ years (males $-66.6 \%$ ). The mean age of the PD group was 69.2 \pm 8.1 years (males $-60 \%$ ).

The mean age of patient's with PSP and PD at the disease onset was 62.5 and 59.0 years respectively. The mean duration of the disease in PSP group was 3.5 years and 3.0 years in PD.

None of the patients had the clinical symptoms of neuropathy. The patients with diabetes mellitus, vitamin B12 and folic acid deficiency or renal failure were excluded.

All patients gave written permission to participate in the study which was approved by ethics committee.

Blink reflex was recorded simultaneously from the right and left orbicularis oculi muscles by the stimulation on each supraorbital nerve with surface electrodes using stimuli with duration of $0.1 \mathrm{~ms}$ and intensity of $20 \mathrm{~mA}$. The single electrical stimulus was repeated 8 times with $10-20 \mathrm{~s}$ intervals. Responses of the orbicularis oculi muscles were recorded by surface electrodes placed below the lower lid localized on the outer edge of the orbiculi. The reference electrode was placed on the area of the chin (Fig. 2).

Recordings of R2 latencies were analyzed automatically with a Keypoint instrument. The R1 latency was abnormal in range of $10.5 \pm 1.6 \mathrm{~ms}$. Abnormal R2 latencies were considered if $\mathrm{R} 2$ response was absent or if ipsilateral and contralateral R2 latencies were above 2SD of normal values $(30.5 \pm 6.8 \mathrm{~ms}$ and $30.5 \pm 8.8 \mathrm{~ms}$, respectively). Interside differences for R2 latencies obtained by Shahani, more than $5 \mathrm{~ms}$, were considered as abnormal [31,32,35].

Conduction velocity in both facial nerves, before blink reflex examination, in every patient with MSA, PSP and PD was performed.

The values of blink reflex registered in healthy volunteers were similar to those reported previously [41,42].

Statistical analysis was performed using Statistica 9.0 software (StatSolf, Tulsa, USA). Statistical significance was defined by attaining a $p$ value $<0.05$.

\section{Results}

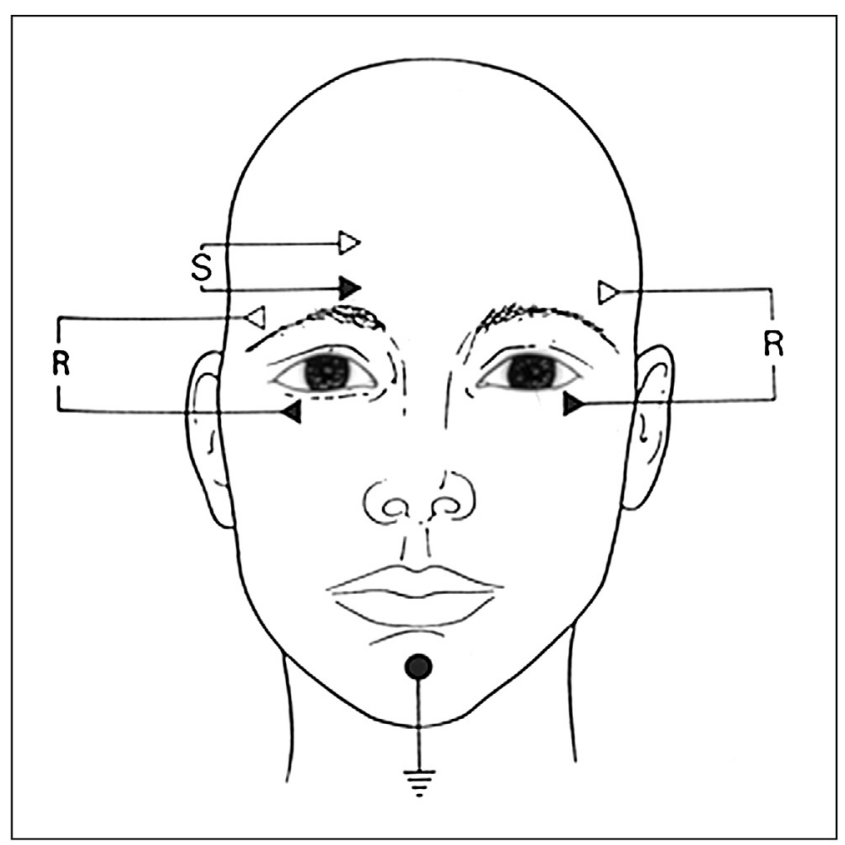

Fig. 2 - Stimulation and recordings of blink reflex.

Conduction velocity parameters in peripheral VII nerves were normal in all the examined patients.

There was significant difference in patient age $(p<0.01)$ between PSP and MSA groups and between PD and MSA groups but there was no difference in duration of the disease between the groups.

The mean values of R1 and R2 blink reflex latencies in MSAC, MSA-P, PSP and PD groups were in normal range (Table 1).

Prolonged R2 latencies of blink reflex were registered in 19 out of 99 individuals (19.2\%) with MSA, PSP or PD.

The most frequently delayed R2 latencies were observed in: PD (in 10 patients; $50 \%$ ), PSP (in 5; 18\%), MSA-C (in 4; 16.6\%) and MSA-P (only in 1; 3.7\%) of examined cases (Fig. 3).

Concerning the individual cases the longest latencies of R1 as well as R2 responses were registered in the PD group.

The statistical differences were recorded mainly between PD and the rest of the examined groups and considered as prolonged ipsilateral and contralateral R2 latencies of blink reflex during both side $(p<0.0001)$. Additionally, ipsilateral R2 latency was statistically longer in MSA-C comparing to MSA-P $(p<0.001)$ and between PSP and MSA-P groups. There were noted longer ipsi and contralateral R2 latencies in patients with PSP $(p<0.0006)$. The most noticeable difference was recorded between PD and MSA-P group $(p<0.0001)$.

The significant difference in the values of ipsilateral and contralateral R2 latencies of blink reflex during both side stimulation between PD and other groups of patients (MSA-C, MSA-P, PSP) were found ( $p<0.0001)$. No significant differences between the values of R1 latency in PD, MSA-C, MSA-P and PSP groups were observed.

The disease onset, duration of the disease, and gender did not show any influence on the result of blink reflex in PSP, MSA-C, MSA-P and PD groups ( $p>0.05)$. 
Table 1 - Blink reflex values in MSA-C, MSA-P, PSP and PD.

\begin{tabular}{|c|c|c|c|}
\hline Diagnosis & $\begin{array}{c}\text { R1 latencies } \\
\text { Stimulation (ms) } \\
\text { Right side } \\
\text { Left side } \\
\text { (ms) } \\
\text { Mean (SD) } \\
\text { Normal value } \\
10.5 \pm 1.6 \mathrm{~ms}(2 \mathrm{SD})\end{array}$ & $\begin{array}{c}\text { R2 latencies } \\
\text { Right side stimulation (ms) } \\
\text { R2 ipsilateral } \\
\text { Mean (SD) } \\
\text { Normal values } \\
\text { (30.5 } \pm 6.8 \mathrm{~ms}) \\
\text { R2 contralateral } \\
\text { Normal value } \\
\text { (30.5 } \pm 8.8 \mathrm{~ms})\end{array}$ & $\begin{array}{c}\text { R2 latencies } \\
\text { Left side stimulation (ms) } \\
\text { R2 ipsilateral } \\
\text { Mean (SD) normal values } \\
\text { (30.5 } \pm 6.8 \mathrm{~ms}) \\
\text { R2 contralateral Normal value } \\
(30.5 \pm 8.8 \mathrm{~ms})\end{array}$ \\
\hline MSA-C & $\begin{array}{l}9.8 \pm 1.3 \\
9.2 \pm 2.1\end{array}$ & $\begin{array}{l}33.4 \pm 4.5 \\
33.9 \pm 2.6\end{array}$ & $\begin{array}{l}32.5 \pm 3.1 \\
34.6 \pm 5.1\end{array}$ \\
\hline MSA-P & $\begin{array}{l}9.4 \pm 0.7 \\
9.4 \pm 0.9\end{array}$ & $\begin{array}{l}28.6 \pm 2.9 \\
30.3 \pm 3.0\end{array}$ & $\begin{array}{l}29.4 \pm 2.9 \\
30.8 \pm 3.4\end{array}$ \\
\hline PSP & $\begin{array}{l}9.7 \pm 1.2 \\
9.5 \pm 1.2\end{array}$ & $\begin{array}{l}32.8 \pm 5.8 \\
34.1 \pm 5.1\end{array}$ & $\begin{array}{l}32.4 \pm 4.5 \\
33.8 \pm 5.3\end{array}$ \\
\hline PD & $\begin{array}{l}9.7 \pm 2.1 \\
9.8 \pm 1.3\end{array}$ & $\begin{array}{l}35.8 \pm 3.8 \\
36.8 \pm 4.8\end{array}$ & $\begin{array}{l}36.6 \pm 4.6 \\
38.1 \pm 3.1\end{array}$ \\
\hline
\end{tabular}

\section{Discussion}

Radiological tests as well as physical exams could be insufficient method in the diagnosis of brainstem pathology. Neurophysiological examinations, such as a blink reflex test persists useful and repeatable tool in estimation of brainstem function. Blink reflex as a polysynaptic arc between the trigeminal and the facial system, estimates brainstem pathways by itself and indicates the influence of nervous system on reticular formation in brainstem. Prolonged latencies of R2 responses registered in $19.2 \%$ of screened patients may suggest central and brainstem pathways damage. The most frequently abnormal R2 latencies were noted in individuals with $\mathrm{PD}$, however the mean values of $\mathrm{R} 2$ latencies were normal in four examined groups.

In literature there was a very limited number of blink reflex studies involving patients with MSA, PSP and PD. In some of them, distinctive abnormality, as well as normal blink reflex

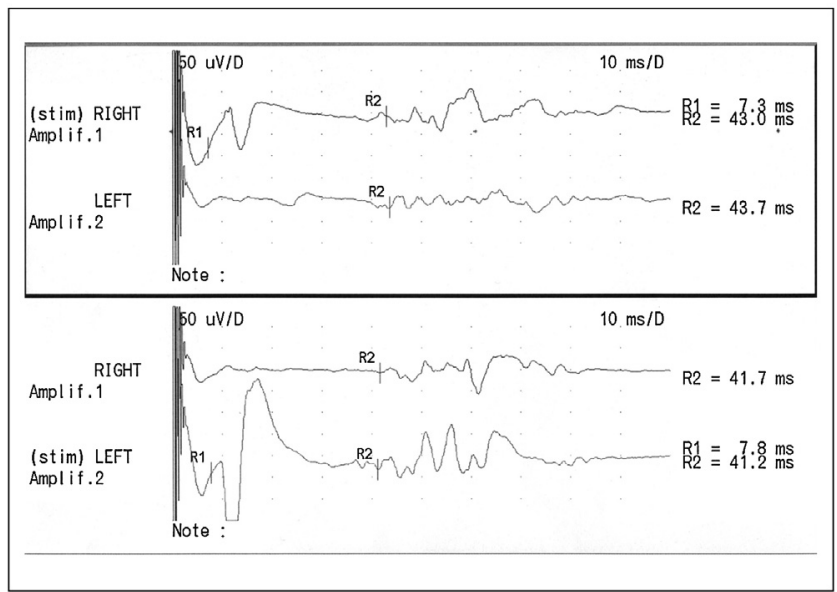

Fig. 3 - Blink reflex in patient with Parkinson disease. R1-R1 (early) response of blink reflex. R2-R2 (late) response of blink reflex. latencies were registered [16,26,31,43-47]. Gironell et al. revealed abnormalities in different brainstem electrophysiological tests in PSP and suggested that degeneration of the pontine reticular formation mainly nucleus reticularis pontis caudatis is present in PSP [48].

Only a few neuropathological studies consider cell depletion and gliosis in anterior horn cells area, as well as in neurons of $\mathrm{V}$ and VII cranials nerves $[6,8,12]$. Prolonged R2 latencies in our patients could indicate dysfunction of reticular brainstem pathways involved in vigilance regulation. Alternatively abnormal blink reflex may also be explained by pathological influence of nitrostriatal pathway on the circuit linking the basal ganglia and brainstem.

Further correlation of blink abnormalities in larger number of patients, with high resolution of MR imaging (7-T) and novel tract imaging technique - Phase Difference Enhanced (PADRE) may at least partially explain the mechanism of delayed latencies observed/recorded in our patients [49].

\section{Conflict of interest}

None declared.

\section{Acknowledgement and financial support}

This study was supported by the statutory grant to the Department of Neurology, Medical University of Warsaw, from the Polish Ministry of Science and Higher Education.

\section{Ethics}

The work described in this article has been carried out in accordance with The Code of Ethics of the World Medical Association (Declaration of Helsinki) for experiments involving humans; Uniform Requirements for manuscripts submitted to Biomedical journals. 


\section{R E F E R E N C E S}

[1] Yoshida M. Multiple system atrophy: $\alpha$-synuclein and neuronal degeneration. Neuropathology 2007;27:484-93.

[2] Gilman S, Low P, Quinn N. Consensus statement on the diagnosis of multiple system atrophy. J Auton Nerv Syst 1998;74:189-92.

[3] Gilman S, Wenning G, Low P, Brooks D, Mathias C, Trojanowski J, et al. Second consensus statement on the diagnosis of multiple system atrophy. Neurology 2008;26 (71):670-6.

[4] Ozawa T, Paviour D, Quinn NP, Josephs KA, Sangha H, Kilford L, et al. The spectrum of pathological involvement of the striatonigral and olivopontocerebellar systems in multisystem atrophy: clinicopathological correlations. Brain 2004;127:2657-71.

[5] Trojanowski J, Revesz T. Proposed neuropathological criteria for the post mortem diagnosis of multiple system atrophy. Neuropathol Appl Neurobiol 2007;33: 615-20.

[6] Su M, Yoshida Y, Hirata Y, Watahiki Y, Nagata K. Primary involvement of the motor area in association with the nigrostriatal pathway in multiple system atrophy: neuropathological and morphometric evaluations. Acta Neuropathol 2001;101:57-64.

[7] Da Rocha A, Maia A, da Siva C, Ferreira N, Barsottini O, Ferraz H. Pyramidal tract degeneration in multiple system atrophy: the relevance of magnetization transfer imaging. Mov Disord 2007;22(2):238-44.

[8] Wennig G, Tison F, Ben-Schlomo Y, Daniel S, Quinn N. Multiple system atrophy: a review of 203 pathological cases. Mov Disord 1997;12:133-47.

[9] Litvan I, Agid Y, Calne D, Campell G, Dubois B, Duvoisin RC, et al. Clinical research criteria for the diagnosis of progressive supranuclear palsy (Steele-RichardsonOlszewski syndrome): report of the NINDS-SPSP international workshop. Neurology 1996;47:1-9.

[10] Katsuse O, Dickson D. Inferior olivary hypertrophy in uncommon in progressive supranuclear palsy. Acta Neuropathol 2004;108(2):143-6.

[11] Shirota Y, Hamada M, Hanajima R, Tereo Y, Matsumotot H, Ohminami S, et al. Cerebellar dysfunction in progressive supranuclear palsy: transcranial magnetic stimulation study. Mov Disord 2010;25(14):2413-9.

[12] Kanazawa M, Shimohata T, Toyoshima Y, Tada M, Kakita A, Morita M, et al. Cerebellar involvement in progressive supranuclear palsy. A clinicopathological study. Mov Disord 2009;24(9):1312-8.

[13] Agosta F, Kostic V, Galantucci S, Mesaros S, Svetel M, Pagani $\mathrm{E}$, et al. The vivo distribution of brain tissue loss in Richardson's syndrome and PSP-parkinsonism: a VBMDARTEL study. Eur J Neurosci 2010;32:640-7.

[14] Longoni G, Agosta F, Kostic V, Stojkovic T, Pagani E, StosicOpincal T, et al. MRI measurements of brainstem structures in patients with Richardson's syndrome, progressive supranuclear palsy-parkinsonism and Parkinson's disease. Mov Disord 2011;26(2):247-55.

[15] Karson CN. Physiology of normal and abnormal blinking. Adv Neurol 1988;49:25-37.

[16] Bologna M, Fasano A, Modugno N, Fabbrini G, Berardelli A. Effects of subthalamic nucleus deep brain stimulation and L-DOPA on blinking in Parkinson's disease. Exp Neurol 2012;235(1):265-72.

[17] Bologna M, Marsili L, Khan N, Parvez AK, Paparella G, Modugno N, et al. Blinking in patients with clinically probable multiple system atrophy. Mov Disord 2014;29 (3):415-20.
[18] Teune LK, Bartels AL, de Jong BM, Willemsen AT, Eshuis SA, de Vries JJ, et al. Typical cerebral metabolic patterns in neurodegenerative brain diseases. Mov Disord 2010;25 (14):2395-404.

[19] Basso MA, Powers A, Evinger C. An explanation form reflex blink hyperexcitability in Parkinson's disease I. Superior colliculus. J Neurosci 1996;16(22):7308-17.

[20] Basso MA, Evinger C. An explanation for reflex blink hyperexcitability in Parkinson's disease. II. Nucleus raphe magnus. J Neurosci 1996;16(22):7318-30.

[21] Han SM, Youn DH. GABA receptor mediated tonic currents in substantia gelatinosa neurons of rat spinal trigeminal nucleus pars caudatis. Neurosci Lett 2008;441(3):296-301.

[22] Yetnikoff L, Lavezzi HN, Reichard RA, Zahm DS. An update on the connections of the ventral mesencephalic dopaminergic complex. Neuroscience 2014;282C:23-48. http://dx.doi.org/10.1016/j.neuroscience.2014.04.010

[23] Jürgens U. Neural pathways underlying vocal control. Neurosci Biobehav Rev 2002;26(2):235-58 [Review].

[24] Deistung A, Schäfer A, Schweser F, Biedermann U, Güllmar U, Trampel R, et al. High-resolution MR imaging of the human brainstem in vivo at 7 Tesla. Front Hum Neurosci 2013;7:710.

[25] Esteban A. A neurophysiological approach to brainstem reflexes. Blink reflex. Neurophysiol Clinique 1999;29:7-28.

[26] Bologna M, Agostino R, Gregori B, Belvisi D, Ottaviani D, Colosimo C, et al. Voluntary, spontaneous and reflex blinking in patients with clinically probable progressive supranuclear palsy. Brain 2009;132:502-10.

[27] Ongerboer de Visser B, Kuypers H. Late blink reflex changes in lateral medullary lesions. Brain 1978;101:285-94.

[28] Bilinska M, Ejma M. The value of the blink reflex and trigeminal somatosensory evoked potentials in the diagnosis of neurological disorders [Wykorzystanie odruchu mrugania i trójdzialnych somatosensorycznych potencjałów wywołanych w diagnostyce neurologicznej]. Pol Prz Neurol 2008;4:87-97.

[29] Filipowska J, Drozdowski W. Assessment of blink reflex in hemiparetic patients after stroke. Neurol Neurochir Pol 1998;32:1405-14

[30] Sommer M, Heise A, Tergau F, Paulus W. Inverse correlation of intracortical inhibition and brain-stem inhibition in humans. Clin Neurophysiol 2002;113:120-3.

[31] Kimura J. The blink reflex as a test for brainstem and higher central nervous system function. In: Desmeth J, editor. New developments in electromyography and clinical neurophysiology. Basel Karger; 1973. p. 682-91.

[32] Kimura J, Rodnitzky R, Van Allen M. Electrodiagnostic study of trigeminal nerve. Orbicularis oculi reflex and masseter reflex in trigeminal neuralgia, paratrigemninal syndrome and other lesions of the trigeminal nerve. Neurology 1970;20:574-83.

[33] Berdardelli A, Cruccu G, Kimura J. The orbicularis oculi reflexes. In: Deutschi G, Elsen A, editors. Recommendations for the practical clinical neurophysiology: guidelines of the international federation of clinical physiology (EEG suppl 52), 6.2. Elsevier Science; 1999. p. 249-53.

[34] Aramidech M, Valls-Sole J, Cruccu G, Ongerboer de Visser B. Cranial nerves and brain stem reflexes electrodiagnostic techniques, physiology and normative data. In: Brown W, Bolton C, Aminoff M, editors. Neuromuscular function and disease. Philadelphia: WB Sanders; 2002. p. 434-54.

[35] Cruccu G, Deuschi G. The clinical use of brainstem reflexes and hand-muscle reflexes. Clin Neurophysiol 2000;111: 371-87.

[36] Cruccu G, Iannetti C, Marx J. Brainstem reflex circuits revisited. Brain 2005;128:386-94.

[37] Brown W, Bolton Ch, Aminoff M. Neuromuscular function and disease, vol. 1. 1993;p. 433-40. 
[38] Bentivollio A, Bressman S, Cassets E. Analysis of blink reflex rate pattern in normal subjects. Mov Disord 1997;12:1028-34.

[39] Hughes AJ, Daniel SE, Kilford L, Lees AJ. Accuracy of clinical diagnosis of idiopathic. Parkinson's disease. A clinicopathological study of 100 cases. JNNP 1992;55:181-4.

[40] Payani CA, Viallet F, Landwehrmeyer BG, NNIPPS Study Group. Disease severity and progression in progressive supranuclear palsy and multiple system atrophy: validation of the NNIPPS - Parkinson Plus Scale. PLoS ONE 2011;6(8):e22293.

[41] Shahani B. The human blink reflex. J Neurol Neurosurg Psychiatry 1970;33:792-4.

[42] Szmidt-Salkowska E, Rowińska-Marcińska K. Blink reflex in motor neuron disease. Electromyogr Clin Neurophysiol 2005;45:313-7.

[43] Valls-Sole J, Valldeoriola F, Tolosa E. Distinctive abnormalities of facial reflexes in patients with progressive supranuclear palsy. Brain 1997;120:1877-83.

[44] Valls-Sole J. Neurophysiological characterization of parkinsonian syndromes. Neurophysiol Clin 2000;30:352-67.
[45] Thompson RF, Steinmetz JE. The role of the cerebellum in classical conditioning of discrete behavioral responses. Neuroscience 2009;162(3):732.

[46] Kızıltan ME, Gunduz A, Kızıltan G, Tekeoğlu A, Sohtaoğlu M. Brainstem and spinal reflex studies in patients with primary progressive freezing of gait. J Neurol Sci 2014;343 (1-2):51-5.

[47] Agostino R, Bologna M, Dinapoli L, Gregori B, Fabbrini G, Accornero N, et al. Voluntary, spontaneous, and reflex blinking in Parkinson's disease. Mov Disord 2008;23 (5):669-75.

[48] Gironell A, Kulisevsky J, Roig C, Pascual-Sedano B, Rodriguez-Fornells A, Otermin P. Diagnostic potential of acoustic startle reflex, acoustic blink reflex and electrooculography in progressive supranuclear palsy: a prospective study. Mov Disord 2003;18:1273-9.

[49] Kakeda S, Korogi Y, Yoneda T, Nishimura J, Sato T, Hiai Y, et al. A novel tract imaging technique of the brainstem using phase difference enhanced imaging: normal anatomy and initial experience in multiple system atrophy. Eur Radiol 2011;21(10):2202-10. 